\title{
Coordination of battery energy storage and power-to-gas in distribution systems
}

\author{
Teodor Ognyanov Trifonov
}

\begin{abstract}
Concerning the rapid development and deployment of Renewable Energy Systems (RES) and Energy Storage System (ESS) including Power-to-Gas (PtG) technology can significantly improve the friendliness of the integration of renewable energy. The purpose of this paper is to develop a coordination strategy between a battery energy storage and a PtG system. A simulation case is created with an electrical and a natural gas grid as well as steady-state models of RES and PtG. Charging strategies are developed accordingly for the ESS as well as production strategies for the PtG system. The size of the ESS is then observed with regards to the RES and PtG systems. As a result, it is found that surplus energy from RES can be stored and then used to support the electrical grid and the natural gas grid. It is also concluded that the capacity of the ESS can be affected, given a proper charging and production strategy, which needs to be tailored to each system. As shown in the paper, due to an improper charging strategy in the first quarter of a month, the ESSPC size has increased from its optimal size of $314 \mathrm{MWh}$ to roughly $576 \mathrm{MWh}$. It can also be seen that given a proper charging strategy, this capacity can be less than $200 \mathrm{MWh}$.
\end{abstract}

Keywords: Electrical energy storage, Power-to-gas, Coordination, Integrated energy systems

\section{Introduction}

In the past few decades, fossil-fuel energy meets most of the energy needs of the world [1]. However, with the high number of environmental problems and the depletion of fossil fuels, renewable energy will be a major electricity source for the power grid and the penetration of renewable energy such as wind and solar power will keep increasing.

According to the German Advisory Council on Global Change, the time to phase out the fossil-fuel-based energy is closer than ever. The turning point should occur around the year 2030 [2], and by then much work needs to be done to make different RES operate more efficiently. This can happen through new technologies, finding specific optimal geographical locations for placing RES or even creating new RES.

Denmark has set an ambitious goal where $100 \%$ of the energy supply must come from RES. So in the next years, it is expected that more and more of the energy supply of the country will be provided by RES, mainly from wind farms (both onshore and offshore). According to relative planning, $50 \%$ of electrical demand should be

Correspondence: trifonovteo91@gmail.com

Faculty of Engineering and Science, Aalborg University, Aalborg, Denmark covered by wind power by 2020 and coal, and oil energy should be phased out from the Danish power system by 2030. By the year 2035 both electricity and heat demand should be met by RES and by the year $2050100 \%$ of energy supply including electrical, heat, industry and transport should be covered by RES [3].

This paper focuses on the 2035 milestone, and in that case, RES will need to cover more than one energy sector thus needing to increase its installed capacity. ESS can be paired together with these RES to store part of the excess energy. Also, a PtG system, which transforms water into a synthetic natural gas (SNG) through the use of electricity, can use the stored electrical energy in the ESS, that is produced by the RES, and use it to help cover the gas needs of consumers [4-6].

This paper aims to contribute to the study of interconnected energy systems and focuses on the coordination between RES and PtG. Through the information presented here, the author has created a program in Matlab called ESSPC (Electrical Storage System and Power to Gas Coordinator), through which a study can be carried out for a test grid for a period. Information can be obtained on different ESS capacities, the optimal number of RES to be installed, how much the community can 
save by adding an ESS and when the ESS is coordinated with a PtG, how much natural gas can be produced and how much that will affect the ESS size. As the RES simulation steps are not shown in this work, refer to materials [7-10], for more information on how the RES are modeled.

The remainder of the paper is organized as follows: Section 2 presents the model that is used in this article, as well as an explanation of how the PtG system is modeled. This section also provides information on how the production strategy for the PtG is formed. Section 3 presents different sizing scenarios for the ESS. Section 4 presents the results from these scenarios. Section 5 is dedicated to conclusions that are formed from this paper.

\section{Methods and Modelling}

The framework of the combined electrical and gas grid is illustrated in Fig. 1. The electric power system consists of consumers, ESS and RES (Wind Turbine and Photovoltaics). The ESS is connected to a PtG system which can transform the stored electrical energy into SNG. Then via the gas network, two Gas Powered Generators (GPGs) can provide electricity for two different areas using the gas produced by the PtG.

In order to help the local consumers of the two cities, with SNG produced from surplus energy from RES, peak regulation is chosen to be performed for each city. This service is selected because GPGs are fast-acting and also the PtG system is not able to produce enough SNG to take care of the base load.

The peak regulation is performed with the help of a load prediction sequence, in an attempt to minimise the gas demand as much as possible. The two load prediction algorithms used are called Kalman Filter and Least Error Squares (LES). Depending on the type of load presented, one of the two algorithms is chosen and the electrical load for the next $24 \mathrm{~h}$ is predicted. Afterwards, if the predicted load is less than the actual load, the GPGs are activated and supply the remaining power that is needed.

\subsection{Power-to-gas model}

In this section, the steps of calculating how much energy the PtG system can withdraw from the ESS are shown.

According to [11], the PtG needs $890.3 \mathrm{~kJ}(\Delta \mathrm{H})$ when $1 \mathrm{~mol}$ of $\mathrm{CO}_{2}$ is turned into $1 \mathrm{~mol}$ of SNG. The energy relationship between electric power and SNG is given by the following equation:

$$
\mathrm{E}_{\mathrm{D}, \mathrm{PtG}}^{(\mathrm{m})}=\mathrm{G}_{\mathrm{D}, \mathrm{PtG}}{ }^{*} \Delta \mathrm{H}^{*} 2.77778 \mathrm{e}^{-7}
$$

Where $G_{D, P t G}$ is Gas demand from the PtG system; $E_{D, P T G}$ is the Energy demand from the PtG system at the moment "( $\mathrm{m})$ ". The energy unit is turned into [MWh] through multiplying $\Delta \mathrm{H}$ by $2.77778 \mathrm{e}-72.77778 e^{-7}$.

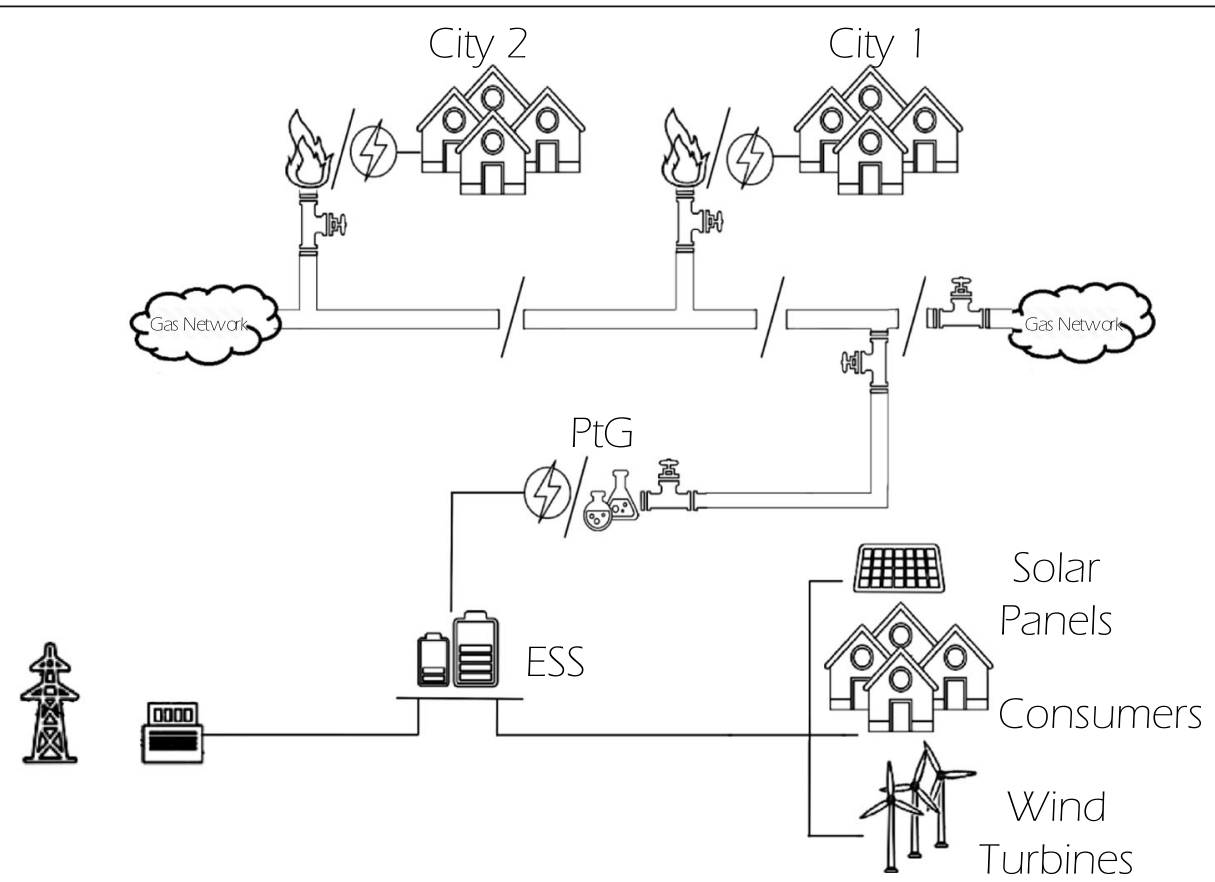

Fig. 1 ESS and PtG model grid layout 
The energy conversion relationship between the gas generation rate and the consumed electric power can be expressed as:

$$
\mathrm{G}_{\mathrm{P}, \mathrm{PtG}}=\mathrm{C}_{\mathrm{PtG}} * \mathrm{E}_{\mathrm{D}, \mathrm{PtG}}
$$

$\mathrm{G}_{\mathrm{PPtG}}$ is the natural gas generation rate of the $\mathrm{PtG}, \mathrm{m}^{3} / \mathrm{h}$; $E_{D, P t G}$ is the consumed electrical power in the process; $\underline{C_{\mathrm{PtG}}}$ is a constant value which can be calculated by:

$$
\mathrm{C}_{\mathrm{PtG}}=\frac{3600 \eta_{\mathrm{PtG}}}{\mathrm{LHV}}
$$

Energy efficiency of the PtG is marked by $\eta \mathrm{PtG}$. The energy density of natural gas is presented via its Lower Heating Value (LHV), MJ/ m3.

The amount of methane that is produced by the PtG can be calculated by the above equations. If the amount of methane needed is known and all the conversion energy is provided by the ESS, the energy withdrawn from the ESS can be given by:

$$
\mathrm{E}_{\mathrm{D}, \mathrm{PtG}}=\frac{\mathrm{G}_{\mathrm{P}, \mathrm{PtG}}}{\mathrm{C}_{\mathrm{PtG}}}
$$

\subsection{Gas grid flow calculations}

To analyze the steady-state flow in the gas grid, the nodal balance equations of the system are presented firstly. Then, to solve the nonlinear model, NewtonRaphson method is adopted which is a popular method in the gas and power system analysis [12].

Firstly, the resistance coefficient of the different pipelines $Z_{\mathrm{k}-1}$ is calculated $Z_{k-l}$.

$$
\mathrm{Z}_{\mathrm{k}-\mathrm{l}}=\left(6.4575 * 10^{-7}\right) * \mathrm{~L}_{\mathrm{k}-\mathrm{l}} / \mathrm{D}_{\mathrm{k}-\mathrm{l}}^{5}
$$

Here $\mathrm{L}$ is the length of the pipe and $\mathrm{D}$ is the diameter and " $\mathrm{k}$ " and "l" refer to the section of the natural gas pipeline. Afterwards, the following nonlinear equations that represent the gas system can be written:

$$
\begin{aligned}
\Delta \Pi_{\mathrm{k}} & =\mathrm{p}_{\mathrm{k}}^{2}-\mathrm{p}_{1}^{2}-\mathrm{Z}_{\mathrm{k}-\mathrm{l}} * \mathrm{Q}_{\mathrm{GAS}, \mathrm{k}-\mathrm{l}} \\
\Delta \mathrm{Q}_{\mathrm{k}} & ==\mathrm{Q}_{\mathrm{S} G A S, \mathrm{k}}-\mathrm{Q}_{\mathrm{D}} \mathrm{GAS}, \mathrm{k}^{-} \sum_{\text {iek }} \mathrm{Q}_{\mathrm{GAS}, \mathrm{k}-\mathrm{l}}
\end{aligned}
$$

Using this information, the Newton-Raphson is implemented with the following equations:

$$
\mathrm{F}(\mathrm{X})=-\mathrm{J}^{*} \Delta \mathrm{X}
$$

To solve the nonlinear equations a point $\mathrm{X}$ must be considered, which is close to the actual solution:

$$
\begin{aligned}
& X=\left[\begin{array}{llllll}
p_{1} & p_{2} & p_{3} & Q_{S G A S, 1} & Q_{S G A S, 1-2} & Q_{S G A S, 2-3}
\end{array}\right]^{T} \\
& \mathrm{~F}(\mathrm{X})=\left[\Delta \Pi_{\mathrm{k}} \Delta \mathrm{Q}_{\mathrm{k}}\right]^{\mathrm{T}}
\end{aligned}
$$

Moreover, the Jacobin matrix is given as:

$$
\mathrm{J}=\left[\begin{array}{cccccc}
\frac{\delta \Delta \Pi_{1}}{\delta \mathrm{p}_{1}} & 0 & 0 & 0 & 0 & 0 \\
\frac{\delta \Delta \Pi_{2}}{\delta \mathrm{p}_{1}} & \frac{\delta \Delta \Pi_{2}}{\delta \mathrm{p}_{2}} & 0 & 0 & \frac{\delta \Delta \Pi_{2}}{\delta \mathrm{Q}_{\mathrm{GAS}, 1-2}} & 0 \\
0 & \frac{\delta \Delta \Pi_{3}}{\delta \mathrm{p}_{2}} & \frac{\delta \Delta \Pi_{3}}{\delta \mathrm{p}_{3}} & 0 & 0 & \frac{\delta \Delta \Pi_{2}}{\delta \mathrm{Q}_{\mathrm{GAS}, 2-3}} \\
0 & 0 & 0 & \frac{\delta \Delta \mathrm{Q}_{1}}{\delta \mathrm{Q}_{\mathrm{GAS}, 1}} & \frac{\delta \Delta \mathrm{Q}_{1}}{\delta \mathrm{Q}_{\mathrm{GAS}, 1-2}} & 0 \\
0 & 0 & 0 & 0 & \frac{\delta \Delta \mathrm{Q}_{2}}{\delta \mathrm{Q}_{\mathrm{GAS}, 1-2}} & \frac{\delta \Delta \mathrm{Q}_{3}}{\delta \mathrm{Q}_{\mathrm{GAS}, 2-3}} \\
0 & 0 & 0 & 0 & 0 & 0
\end{array}\right]
$$

Thus, a load flow sequence for the natural gas grid is created.

\section{Optimal sizing of the ESS in coordination with the PtG}

This paper presents three methods for sizing the storage system. The first method sizes the storage system depending on the exported energy from the local grid (overproduction from the RES) and the imported energy from other interconnected power systems. The second method is where the import/export of the grid is monitored, as well as the price of electricity. The third method is created based on analysis of the first two approaches, where the best one is chosen, and coordination between the ESS and the PtG is performed. This is done so that a clear distinction can be made, whether adding a PtG to a system with ESS can further on improve the size of the storage system,

The network presented in Fig. 1, contains RES, wind turbines and photovoltaics. ESSPC needs to be supplied with electrical consumption data, grid parameters and weather data (wind speed and humidity) for some days. Through the weather data, different turbine and photovoltaic manufacturers can be reviewed for whether or not their production fits the area, both in production and whether the weather conditions are optimal for that technology.

Equation 12 presents how the power generation from all the RES in the network is obtained.

$$
\mathrm{P}_{\mathrm{G}, \mathrm{G}}^{(\mathrm{m})}=\mathrm{P}_{\mathrm{Gn}, \mathrm{WT}}^{(\mathrm{m})} * \mathrm{x}_{\mathrm{n}}+\mathrm{P}_{\mathrm{GN}, \mathrm{PV}}^{(\mathrm{m})} * \mathrm{y}_{\mathrm{n}}
$$

Here, " $m$ " refers to the given moment from the steadystate data. $\mathrm{P}_{\mathrm{G}, \mathrm{G}}$ is the power generated in the grid [MW], $P_{G n, W T}$ and $P_{G n, P V}$, refer to the power produced by the wind turbines and the photovoltaics under the effect of the weather. To size the ESS, the number of RES installed in the grid needs to be varied. This is set through " $x$ " and " $y$ " in Eq. 12. Obtaining the optimal number of RES can be found by testing different 
combinations of RES and thus finding the most optimal ESS size.

$$
\mathrm{P}_{\mathrm{G}, \mathrm{G}}^{(\mathrm{m})}=\mathrm{P}_{\mathrm{G} 1, \mathrm{WT}}^{(\mathrm{m})} * \mathrm{x}_{1}+\mathrm{P}_{\mathrm{G} 2, \mathrm{WT}}^{(\mathrm{m})} * \mathrm{x}_{2}+\mathrm{P}_{\mathrm{G} 1, \mathrm{PV}}^{(\mathrm{m})} * \mathrm{y}_{1}
$$

Equation 13 presents a case where two wind turbine technologies are tested and one photovoltaic technology. Each wind turbine and photovoltaic technology have a minimal and maximal number of installed units in the network, set by the user. Through varying $\times 1, \times 2$ and $y$, the power generation in the network for each combination for each period is found. After simulation of all possible results, the smallest ESS size is found and traced back to its RES combination.

\subsection{Sizing storage system with regards to the import/ export}

The first method for sizing the ESS is used with eqs. 1416. Here, the ESS is sized only through using a percentage of the residual power in the given electrical network.

$$
\mathrm{P}_{\mathrm{IO}, \mathrm{SS}}^{(\mathrm{m})}=\mathrm{P}_{\mathrm{R}, \mathrm{G}}^{(\mathrm{m})} * \mathrm{R}_{\mathrm{PER}}
$$

$P_{R, G}$ is the extra grid power, the difference between the generated and consumed power in the grid at data point " $m$ ". $R_{\text {PER }}$ is user-set and refers to what percentage of the residual power value must charge/discharge the ESS. When the residual power value is positive, the excess energy is transferred to other interconnected networks. A percentage (Rper) of that power is used for charging the storage system. When the residual energy in the grid is negative, a percentage (Rper) of the necessary electric power is supplied from the ESS. This way the ESS can support the local network, where the RES are installed. The power that is charged/discharged in the ESS is given by $\mathrm{P}_{\mathrm{IO}, \mathrm{SS}}$.
After determining whether the storage system must perform a charging or discharging action, for that specific moment, the new ESS capacity can be found.

$$
\mathrm{E}_{\mathrm{CAP}, \mathrm{SS}}^{(\mathrm{m})}=\mathrm{E}_{\mathrm{CAP}, \mathrm{SS}}^{(\mathrm{m}-1)}+\mathrm{P}_{\mathrm{I} / \mathrm{O}, \mathrm{SS}}^{(\mathrm{m})}
$$

This action is performed for every data point, and the ESS charge state is updated for every data point. To obtain what the total storage capacity for the observed period must be, information is needed on the lowest and highest $\mathrm{E}_{\mathrm{CAP}, \mathrm{SS}}$ has reached for the entire dataset.

$$
\mathrm{E}_{\mathrm{CAP}, \mathrm{SS}}=\max \left(\mathrm{E}_{\mathrm{CAP}, \mathrm{SS}}\right)-\min \left(\mathrm{E}_{\mathrm{CAP}, \mathrm{SS}}\right)
$$

Equation 16 presents the total storage capacity for the entire dataset, given the current number of RES. An example is provided in Fig. 2. There, a specific size can be traced to each RES technology. The optimal number of RES for obtaining that ESS size is the combination of all RES that matches that specific size.

\subsection{Sizing storage system with regards to the import/ export and the price of electrical power}

The second method for sizing the ESS monitors the import/export power in the study grid and also oversees the price of electricity. Here, for every discharge action, the ESS must perform, the price of importing electricity from the interconnected network is also monitored. If the price of importing electricity into the studied grid is below a certain threshold, set by the researcher, the ESS performs no discharge action. On the other hand, when the price of importing electricity is too high, the test grid is supplied power through the ESS. For this method, another action must be performed before sizing the ESS, and that is to run the test grid through a power flow algorithm. This is done so that a more accurate model can be created, where the power loss in the grid is taken into
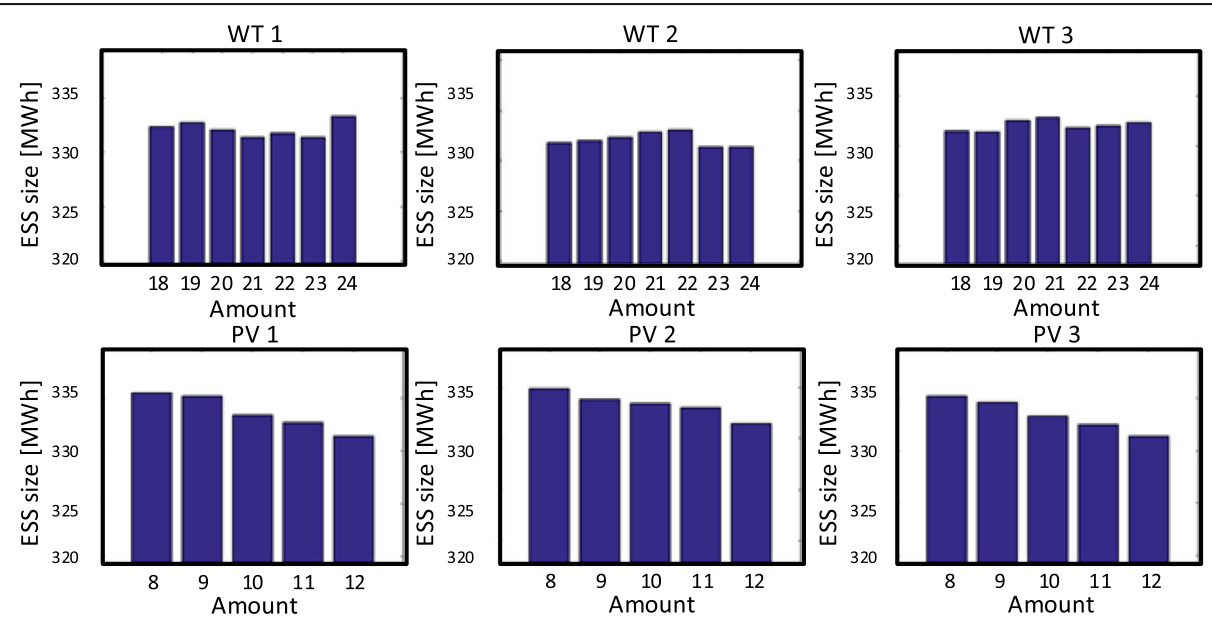

Fig. 2 RES combinations 
account. For ESSPC, which is created in Matlab, the Matpower [13] toolbox is used. Equations. 17 to 24 present the explained method mathematically. Equation 17 is used in the event where the power that is generated in the grid $\left(\mathrm{P}_{\mathrm{G}, \mathrm{G}}\right)$ by the RES is greater than the total consumption $\left(\mathrm{P}_{\mathrm{C}, \mathrm{G})}\right.$ that is needed in the test grid at that point in time. In such an event, after accounting for the pre-set residual percentage, the ESS is charged $\mathrm{P}_{\mathrm{C}, \mathrm{SS}}$. Because for MATPOWER, the ESS acts like a generator and a motor at the same time, in the event of charging the ESS, the generation of the ESS $\left(\mathrm{P}_{\mathrm{G}, \mathrm{SS}}\right)$ must be set to zero.

$$
\begin{aligned}
& \mathrm{P}_{\mathrm{C}, \mathrm{SS}}^{(\mathrm{m})}=\left(\mathrm{P}_{\mathrm{G}, \mathrm{G}}^{(\mathrm{m})}-\mathrm{P}_{\mathrm{C}, \mathrm{G}}^{(\mathrm{m})}\right) * \mathrm{R}_{\mathrm{PER}} \\
& \mathrm{P}_{\mathrm{G}, \mathrm{SS}}^{(\mathrm{m})}=0
\end{aligned}
$$

If the power consumption is greater than the generation, and the price for importing power from the interconnected grid $\left(\mathrm{P}_{\mathrm{PRI}, \mathrm{G}}\right)$ is greater than the set power price limit $\left(\mathrm{P}_{\mathrm{PR}, \mathrm{G}}\right)$, it is determined that it is too expensive to import power, and as such the ESS supplies all the necessary power to the consumers.

$$
\begin{aligned}
& \mathrm{P}_{\mathrm{G}, \mathrm{SS}}^{(\mathrm{m})}=\left(\mathrm{P}_{\mathrm{C}, \mathrm{G}}^{(\mathrm{m})}-\mathrm{P}_{\mathrm{G}, \mathrm{G}}^{(\mathrm{m})}\right) * \mathrm{R}_{\mathrm{PER}} \\
& \mathrm{P}_{\mathrm{C}, \mathrm{SS}}^{(\mathrm{m})}=0 \\
& \mathrm{P}_{\mathrm{PRI}, \mathrm{G}}^{(\mathrm{m})}>\mathrm{P}_{\mathrm{PR}, \mathrm{G}}^{(\mathrm{m})}
\end{aligned}
$$

In the event, where the price of electricity is low enough, the ESS does not perform any action.

$$
\begin{aligned}
& \mathrm{P}_{\mathrm{C}, \mathrm{SS}}^{(\mathrm{m})}=0 \\
& \mathrm{P}_{\mathrm{G}, \mathrm{SS}}^{(\mathrm{m})}=0 \\
& \mathrm{P}_{\mathrm{PRI}, \mathrm{G}}^{(\mathrm{m})}<\mathrm{P}_{\mathrm{PR}, \mathrm{G}}^{(\mathrm{m})}
\end{aligned}
$$

To find the size of the ESS, Eqs. 15 and 16 are used. Here $\mathrm{P}_{\mathrm{I} / \mathrm{O}, \mathrm{SS}}$ is either $\mathrm{P}_{\mathrm{C}, \mathrm{SS}}$ or $\mathrm{P}_{\mathrm{G}, \mathrm{SS}}$, depending on the action that the ESS must perform at that moment.

This method allows the researcher to make a more educated decision whether the RES are suitable for the current area based on information about how costly it is going to be to supply the test grid when the RES is not producing. It also allows for sizing the ESS, depending on the cost of importing electricity into the test grid, when the RES is not working.

\section{Numerical simulation}

The following section presents the results for three different cases-sizing ESS capacity.

\subsection{Model information}

The electricity demand data is obtained from [14] and is given in hourly intervals for one month. The RES production is achieved via weather data, obtained at a given moment and location. The wind power generation is determined by the air density and wind speed. Such data is obtained from [15] in the form of hourly intervals. The hourly solar irradiance and the temperature are obtained from [16] for the Photovoltaics. Moreover, from [17] the hourly electrical price has been obtained.

To simulate the working process of the natural gas grid, some initial information is needed. In this case, that would be the diameter and length of different pipes in the network.

$$
\begin{aligned}
& \mathrm{D}_{0-1}=280 \mathrm{~mm} \mathrm{D}_{1-2}=250 \mathrm{~mm} \mathrm{D}_{2-3}=250 \mathrm{~mm} \\
& \mathrm{~L}_{0-1}=10 \mathrm{~km} \mathrm{~L}_{1-2}=13 \mathrm{~km} \mathrm{~L}_{2-3}=12 \mathrm{~km}
\end{aligned}
$$

Aside from that, the gas flow rate in the pipeline once it enters the observed part of the network is needed and at what pressure.

$$
\begin{aligned}
& \mathrm{Q}_{\mathrm{GAS}, 0-1}=15000\left[\mathrm{~m}^{3} / \mathrm{h}\right] \\
& \mathrm{p}_{0}=1000[\mathrm{kPa}]
\end{aligned}
$$

To create the steady-state model, information about the gas consumption of the two GPGs is required. That is obtained the method explained in section 2 .

\subsection{Sizing storage system capacity with surplus power}

Figure 3 presents the behavior of the ESS and the effect it will have on the grid. The first plot presents how the energy inside the ESS changes over the course of the month and the second plot presents the amount of power that is charged or discharged from the ESS every hour. It can be seen that the ESS capacity profile is represented by some different in size hills. Each hilltop represents the end of a cycle of positive RES surplus power, and each valley bottom represents the end of a cycle where the RES could not meet the demand. Also, from the second plot, it can be noticed that due to the highly fluctuating power production, due to the effect of the RES, the charging power at times is more than twice of what is discharged for the whole period. It is also observed that the discharge profile mostly falls in the same window when compared to the charging profile for the entire period.

\subsection{Sizing storage system capacity with surplus power and price method}

The next charging method that includes the price of electricity is executed. The number of RES stays the same as the number of RES as before. Here, it can be 


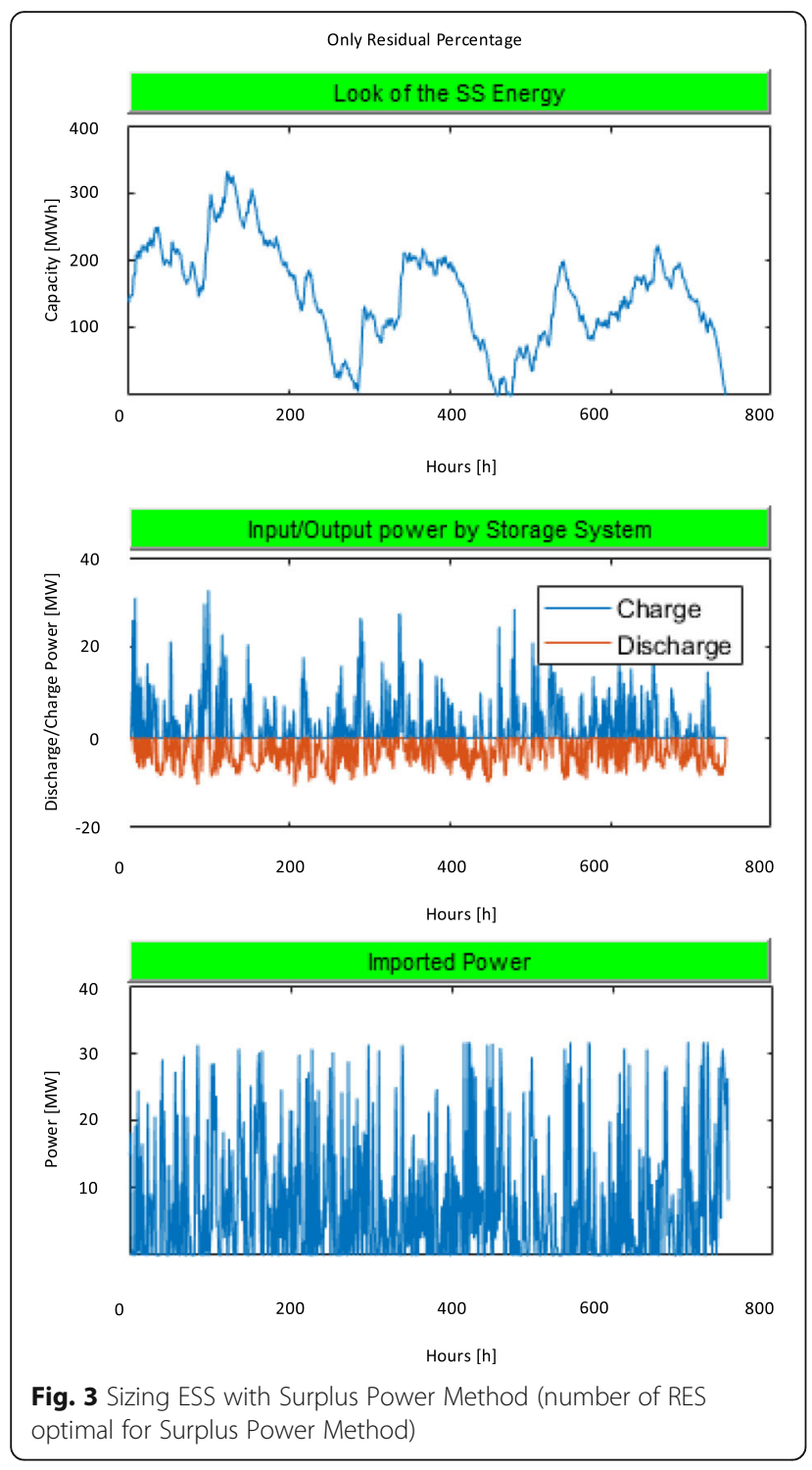

seen that the ESS is constantly charging for the whole period. The reason for this behavior is the significant number of RES that is present. Because the number of RES is greater than what this method needs, the ESS almost constantly charges throughout the whole period and at the end reaches a size of around $1800 \mathrm{MWh}$. It can also be seen that the charging cycles have not increased in number, compared to Fig. 3, but some have increased in power. However, the biggest change, which also affects the ESS, is the lack of discharging cycles in the middle of the given period. This is due to the change of charging strategy, and those areas where it is noticed a lack of discharging events correspond to the low price of electricity, deducted from 3.2. With that information in mind, it is deduced that the PtG must be paired together with an ESS that uses the Surplus Power and Price method.
An overview of all the results obtained in sizing the ESS with the above methods can be observed in Table 1 . The first row presents the total amount of money that has been paid for imported power. It can be seen that with no ESS, that value is around 414,460 \$, while with a $331 \mathrm{MWh}$ ESS using the Surplus Power method, that value is around 342,670 \$. Using the Surplus Power and Price method with this configuration brought worse results regarding the price paid, 376,880 \$ and size of the ESS, 1830 MWh. The last two rows, showing the highest and lowest discharge rate, are the same for both ESS for both methods.

As mentioned before, the case presented Fig. 4 is obtained with some RES that is optimal for the Surplus Power Method and not the Surplus Power and Price Method. Through finding the optimal number of RES for the Surplus Power and Price, via ESSPC, a size of roughly $314 \mathrm{MWh}$ is obtained, which is slightly smaller than for the other method.

Figure 5 presents the capacity profile of the ESS working with the PtG. In order to get this optimal profile, ten more Wind Turbines had to be added than for the case in 4.3, but on the other hand, the number of Solar Arrays was decreased by 7 . Now, the discharge events have a slightly higher number and are slightly larger, and there are also discharges in places where there were no before. This is due to the charging strategy when the price is within the predetermined limits, in the first case the grid did not need the ESS, but in the example that is shown in Fig. 5, the ESS is still required. Another reason for the different shape of the ESS capacity is the effect of the PtG system. Because the PtG supports two GPGs that perform peak regulation, we can see that their SNG needs steadily affect the storage system (because SNG is created with energy from the ESS). Due to that, it can be

Table 1 Sizing ESS without PtG (portion)

\begin{tabular}{|c|c|c|}
\hline \multicolumn{3}{|c|}{ Total Price Paid for Imported Power Whole Period [\$] } \\
\hline No Storage & Surplus Power Method & $\begin{array}{l}\text { Surplus Power and Price } \\
\text { Method }\end{array}$ \\
\hline $4,14 \mathrm{E}+05$ & $3,43 E+05$ & $3,77 E+05$ \\
\hline \multicolumn{3}{|c|}{ Total Size of the Storage System [MWh] } \\
\hline No Storage & Surplus Power Method & $\begin{array}{l}\text { Surplus Power and Price } \\
\text { Method }\end{array}$ \\
\hline 0 & 331,4224 & $1,83 \mathrm{E}+03$ \\
\hline \multicolumn{3}{|c|}{ Highest Charge Rate [MW/interval] } \\
\hline No Storage & Surplus Power Method & $\begin{array}{l}\text { Surplus Power and Price } \\
\text { Method }\end{array}$ \\
\hline 0 & 30,995 & 30,995 \\
\hline \multicolumn{3}{|c|}{ Highest Discharge Rate [MW/interval] } \\
\hline No Storage & Surplus Power Method & $\begin{array}{l}\text { Surplus Power and Price } \\
\text { Method }\end{array}$ \\
\hline 0 & 10,7622 & 10,7622 \\
\hline
\end{tabular}




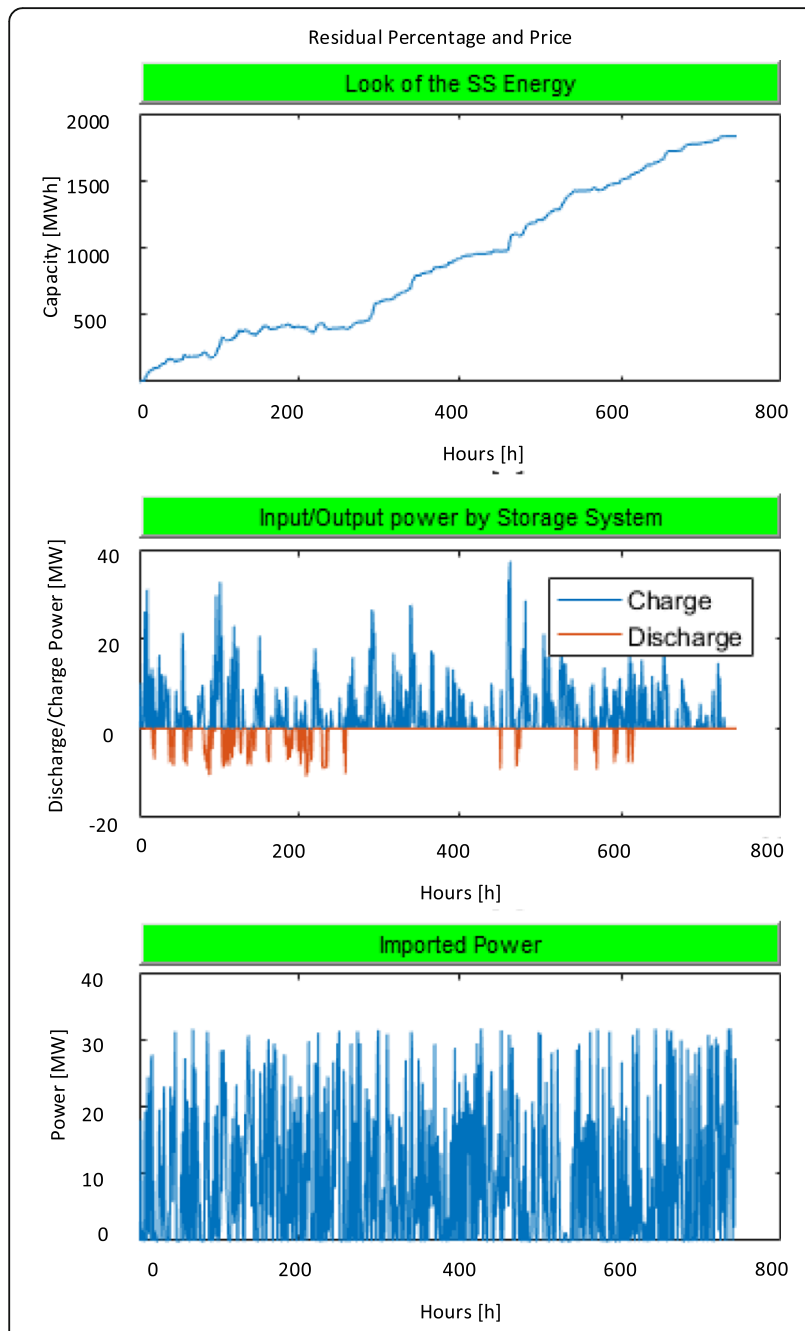

Fig. 4 Sizing ESS with Surplus Power and Price Method (number of RES optimal for Surplus Power Method)

seen that a point is reached, in the middle of the period, where the storage can barely keep up in charging with RES energy. This is the reason why the size is relatively bigger for this ESS than from the one before, as every ESS so far starts its working period optimally charged, the ESS for this case had to be almost entirely charged (due to the PtG load) and that affected the number of RES, making it higher.

The results can be observed in Table 2. Due to the increased number of RES, the total price paid for imported power has decreased, but it is still a bit higher than the total price paid for imported power with no ESS and PtG. The total ESS capacity has also increased from 314 MWh to roughly $576 \mathrm{MWh}$, which is a change once again brought by the PtG.

This information is proof that for the currently chosen Grids, Consumers, and RES, the combination of ESS and PtG will not bring better results in
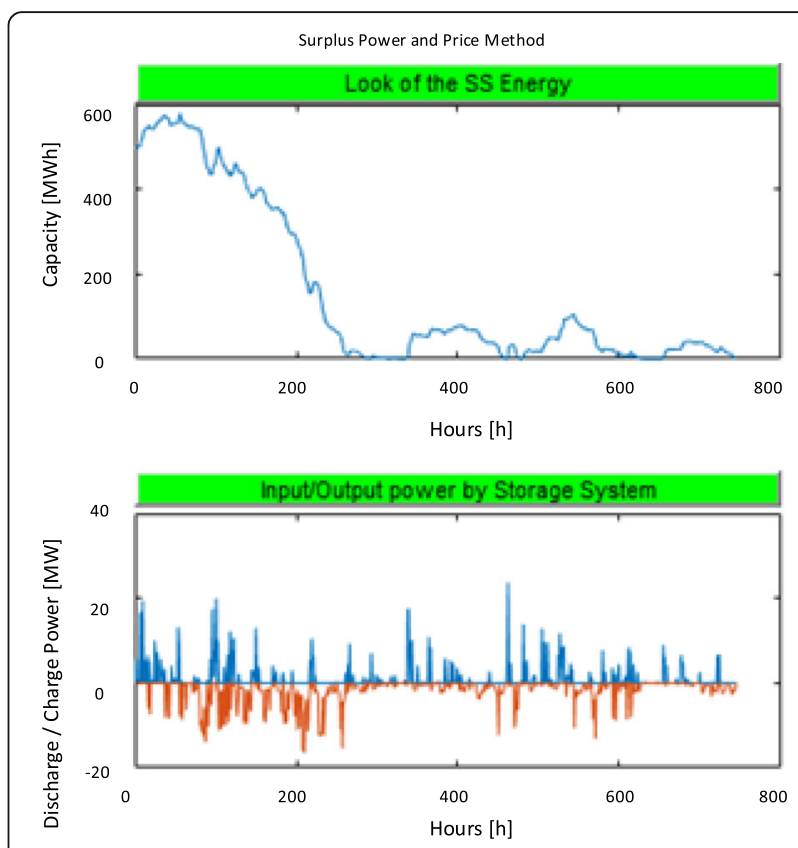

Fig. 5 Sizing ESS with Surplus Power and Price Method with PtG

lowering the ESS capacity. It can be deduced that the PtG has the potential of lowering the ESS, given slightly different starting conditions, like changing the demand profiles, the prediction algorithms and introducing various more RESs.

\section{Conclusions}

Coordination between ESS and PtG systems will play a major role in the future power system. Due to the large number of RES that are installed and will continue to be installed, a method for utilizing the excess renewable

Table 2 Sizing ESS with PtG

Total Price Paid for Imported Power Whole Period [\$]

$\begin{array}{ll}\text { No Storage } & \text { Surplus Power and Price Method } \\ 4,03 E+05 & 4,33 E+05\end{array}$

Total Size of the Storage System with PtG [MWh]
No Storage
Surplus Power and Price Method
0
$5,76 \mathrm{E}+02$

Gas Produced entire period [m^3]

$$
\begin{array}{ll}
\text { No Storage } & \text { Surplus Power and Price Method } \\
0 & 7,03 \mathrm{E}+04
\end{array}
$$

Highest Charge Rate [MW/interval]

$$
\begin{array}{ll}
\text { No Storage } & \text { Surplus Power and Price Method } \\
0 & 1,94 \mathrm{E}+01
\end{array}
$$

Highest Discharge Rate [MW/interval]

$$
\begin{array}{ll}
\text { No Storage } & \text { Surplus Power and Price Method } \\
0 & 1,32 \mathrm{E}+01
\end{array}
$$


energy is needed. It is found out that it is possible to store surplus energy from RES and store it as electrochemical energy, which afterward can be turned into methane. With the proper charging strategy, tailored to the given area, the size of the ESS can be optimised to be as small as possible.

Furthermore, by setting the gas demand strategies with load prediction algorithms, it was found that using the PtG system under these initial conditions will increase the ESS size. The ESS size in coordination with a PtG system can potentially be lowered by studying various grid layouts, improvement of the gas demand strategies or even implementation of a gas storage facility in the grid.

\section{Competing interests}

The author declares that he/she has no competing interests.

Received: 30 May 2017 Accepted: 13 October 2017

Published online: 17 November 2017

\section{References}

1. D. G. Rachel Carnegie, David Nderitu, Paul V. Preckel, "utility scale energy storage systems," state utility forecasting Group 2013

2. ISPRE, "Research and Development on Renewable Energies" ISPRE2011.

3. (1/9). Available: https://ens.dk/sites/ens.dk/files/contents/material/file/the_ danish_energy_model.pdf.

4. B. V. L. Mathiesen, Henrik; Hansen, Kenneth; Skov, Iva Ridjan; Djørup, Søren Roth; S. S. Nielsen, Peter; Thellufsen, Jakob Zinck; Grundahl, Lars; Lund, Rasmus, and D. W. C. Søgaard; Drysdale, David; Østergaard, Poul Alberg, "IDA's Energy Vision 2050: A Smart Energy System strategy for 100\% renewable Denmark," Aalborg University 2015.

5. L. Bird, M. Milligan, and D. Lew, "Integrating variable renewable energy: Challenges and solutions," National Renewable Energy Laboratory, Technical ReportSeptember 20132013.

6. Mathiesen, B. V., Lund, H., Connolly, D., Wenzel, H., Østergaard, P. A., Möller, B., et al. (2015). Smart energy systems for coherent 100\% renewable energy and transport solutions. Applied Energy, vol. 145, 139-154, 5/1.

7. Richardson, R. D., \& McNerney, G. M. (1993). Wind energy systems. Proc IEEE, 81, 378-389.

8. S. B. Armando Bellini, Vincenzo lacovone, Cristina Cornaro, "simplified model of a photovoltaic module," 2009.

9. WXWGDA. (2004). Capel, "A novel modeling method for photovoltaic cells," Presented at the power electronics specialists conference. PESC 04. 2004 IEEE 35th annual 2004

10. K. Provence, "calculating PV Array voltage," ed, 2013.

11. Zeng, Q., Fang, J., Li, J., \& Chen, Z. Steady-state analysis of the integrated natural gas and electric power system with bi-directional energy conversion. Applied Energy.

12. P. S. J. H. Lukas Grond, Systems analyses power to gas, KEMA Nederland B.V, Technology Review20/06 2013.

13. Zimmerman, R. D., Murillo-Sanchez, C. E., \& Thomas, R. J. (2011). MATPOWER Steady-state operations, planning, and analysis tools for power systems research and education. IEEE Trans Power Syst, 26, 12-19.

14. "Distribution Zone Substation Information," Ausgrid, Ed., ed: Ausgrid, 2016.

15. "Modern-Era Retrospective Analysis for Research and Applications (MERRA) version 2," ed. gmao.gsfc.nasa.gov: National Aeronautics and Space Administration (NASA)/Goddard Space Flight Center, 2016.

16. "CAMS Radiation Service v2.7 all-sky irradiation (derived from satellite data).", ed: MINES ParisTech (France), 2016

17. "National Electricity Market Price," AEMO, Ed., ed: AEMO, 2016.

\section{Submit your manuscript to a SpringerOpen ${ }^{\odot}$ journal and benefit from:}

- Convenient online submission

- Rigorous peer review

- Open access: articles freely available online

- High visibility within the field

- Retaining the copyright to your article

Submit your next manuscript at $\boldsymbol{\nabla}$ springeropen.com 